\title{
Modelling and test of a thermally-driven phase-change nonmechanical micropump
}

\author{
Y J Song ${ }^{1,2}$ and T S Zhao ${ }^{1,3}$ \\ ${ }^{1}$ Department of Mechanical Engineering, The Hong Kong University of Science and \\ Technology, Clear Water Bay, Kowloon, Hong Kong, People's Republic of China \\ ${ }^{2}$ Department of Chemical Engineering, Beijing Institute of Petrochemical Technology, \\ Beijing 102600, People's Republic of China \\ E-mail: metzhao@ust.hk
}

Received 6 July 2001, in final form 1 October 2001

Published 12 October 2001

Online at stacks.iop.org/JMM/11/713

\begin{abstract}
A thermally driven phase-change nonmechanical micropump has been investigated theoretically and experimentally. This micropump consisted of a microchannel and a number of uniformly-spaced heating elements along the channel. The pumping of fluids in such a pump was realized by using the actuation of a moving vapour slug (bubble) generated by suitably phased heating elements. The pumping mechanism was studied theoretically by considering a liquid-filled tube heated locally by a moving heating source. To verify the theoretical analysis, a pumping device consisting of a microchannel with twelve embedded heaters along the channel was fabricated and tested using deionized water as the working fluid. The experimental results indicate that this simple micropump can achieve a maximum pressure head of $57 \mathrm{~mm} \mathrm{H}_{2} \mathrm{O}$ and a maximum volumetric flow rate of $300 \mu \mathrm{min}^{-1}$ when it is operated for a heating power ranging from 8.0 to $12.0 \mathrm{~W}$ and a heating time of about $3 \mathrm{~s}$. It is found that the theoretical model is in reasonable agreement with the experimental data.
\end{abstract}

\section{Introduction}

Numerous fluidic applications in the areas of medicine, chemistry and environmental testing call for the development of micropumps that can efficiently and reliably handle pure fluids and particulate-laden fluids. To meet this need, a number of micropumps fabricated with microelectromechanical system (MEMS) techniques have been reported in the literature [1-3]. Most of the proposed micropumps are just 'micro versions of traditional pumps', which are characterized by mechanical valves connected to a chamber with oscillation volume. When functioning correctly, valves usually serve their function but often introduce many reliability problems. For instance, valves often leak with use and affect long-term reliability. In addition, valves are often delicate components that must be carefully manufactured and installed for pump reliability. These complications in macroscale pumps are often magnified when they are scaled down into micropumping devices by MEMS techniques, where the choice of materials is limited and assembly is impractical. Furthermore, a relatively

3 Author to whom correspondence should be addressed. large force is needed to activate leak-free microvalves, prompting the development of various schemes to actuate valves. For these reasons, the idea of the microscale pumping without the use of valves or other small moving components becomes rather appealing [4].

It is possible to move liquids and constituents in liquids without using any moving parts. For nonmechanical micropumps, most of the techniques presented in the literature use a variety of electric-fluid interaction phenomena to generate forces on the liquids. For example, fluid motion can be induced by travelling flexural waves for the transport of liquids. A liquid moves in the direction of wave propagation with a speed proportional to the square of the acoustic amplitude. A maximum speed of $130 \mathrm{ml} \mathrm{s}^{-1}$ was observed with a driving voltage of $7.1 \mathrm{~V} \mathrm{rms}$ at $3.5 \mathrm{MHz}$ [5]. Another example of nonmechanical pumping by electricfluid interaction phenomena is the electro-osmosis micropump. Electro-osmosis is a macroscopic phenomenon and involves the pumping of liquid through a capillary tube by an externally applied electric field [6]. A prerequisite for electro-osmosis is the presence of immobilized surface charges at the capillary 


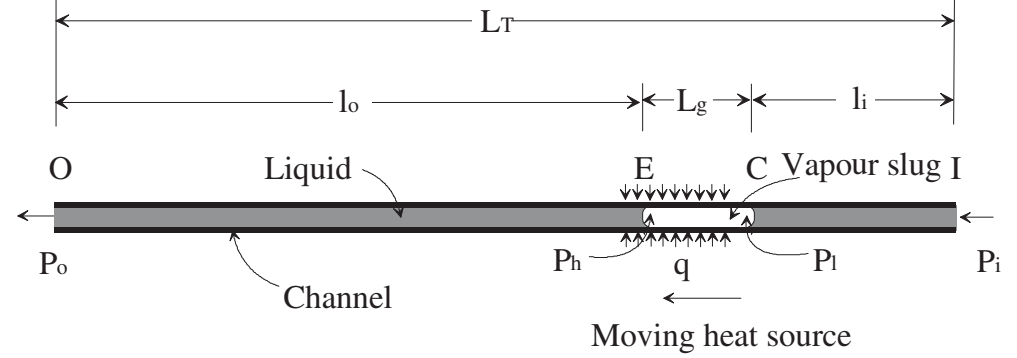

Figure 1. Physical model of the theoretical analyses.

wall in contact with an electrolyte solution. This surface charge leads to the formation of an electric double layer by attracting oppositely charged ions from the buffer and therefore leads to concentration and charge density gradients in the immediate vicinity of the wall. A manifold of capillary channels can be fabricated in a planar glass substrate to control liquid flow in different directions so that the switching of liquid flow between channels can be obtained. A further example concerning the use of electric-fluid interaction phenomena is the electrohydrodynamic micropump. A first attempt at constructing an electrohydrodynamic micropump for the displacement of charged liquids has been reported in [7].

Nonmechanical pumps with moving parts can be designed based on thermally driven liquid-vapour phase change. Some works on using phase change to actuate fluid flow in microchannels and microstructures have been reported. Lin et al [8] presented a microbubble powered actuator. The principle of the actuation was the local heating of a polysilicon line resistor in order to create a single, controllable microbubble that expanded and lifted the actuator plane formed at the end of a microcantilever beam. The displacement of this actuator was stable and was controllable by adjusting the input current that changed the bubble size and subsequently, changed the actuator plate displacement. Bergstrom et al [9] reported a similar microactuation scheme based on thermally driven liquid-vapour phase change in a partially filled sealed cavity. To actuate a fluid flow in a microchannel, new pumping mechanisms based on liquid-vapour phase change have recently been reported $[10,11]$. This newly devised pump consisted of a microchannel and an array of heating elements (three heaters at least) and was fabricated by the silicon micromachining technique. By scanning electric current that was supplied through the heaters with different phases cyclically, liquid in the channel was evaporated and condensed and pumped toward the scanning direction. The pumping of fluids in microchannels using the movement of a single or multiple bubbles has also been reported in $[4,12]$. Their experimental results for a pumping device made of a $3.4 \mu \mathrm{m}$ channel showed pumping of isopropanol at a flow rate

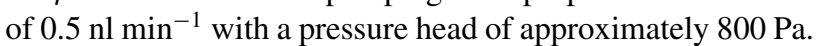

The objective of this study was to investigate theoretically and experimentally a thermally driven phase-change nonmechanical micropump, which consisted of a microchannel and a number of uniformly-spaced heating elements along the channel. The pumping of fluids in such a pump is realized using the actuation of growth and collapse of vapour bubbles generated by suitably phased heating elements. To facilitate a theoretical analysis to the pumping mechanism, we considered a liquid-filled microtube heated locally by a moving heating source. The theoretical analysis was verified by fabricating and testing a pumping device consisting of a microchannel with twelve embedded heaters along the channel.

\section{Pumping mechanism and theoretical analysis}

We now consider a liquid-filled microtube (with diameter $d$ and length $L_{\mathrm{T}}$ ) with its inlet and outlet designated, respectively, by symbols ' $\mathrm{I}$ ' and 'O', as depicted in figure 1. As the microchannel is heated locally by a moving heating source with a sufficiently high heating power $q$, a moving vapour slug (with a length $L_{\mathrm{g}}$ ) forms, with its evaporation front and condensation front denoted by symbols ' $E$ ' and ' $C$ '. Due to evaporation, the pressure at point $\mathrm{E}\left(P_{\mathrm{h}}\right)$ is higher than at point $\mathrm{O}$ such that a positive pressure gradient is established, causing the liquid to flow towards the outlet of the microchannel. On the other hand, due to condensation, the pressure at point $\mathrm{C}\left(P_{1}\right)$ is lower than at point $\mathrm{I}$, resulting in the liquid motion from the inlet $\mathrm{I}$ to point C. As such, a net fluid displacement in the microchannel is realized as the heating source moves from the inlet to the outlet of the microchannel.

The above-described pumping mechanisms can be realized practically using the actuation of the bubbles generated in sequence by a number of heaters distributed along the channel. As an illustrative example, figure 2 demonstrates the moving vapour slug generated in sequence by three heaters. It is seen from this figure that as the heaters are progressively switched on and off, vapour slugs form and collapse in the channel such that the desired pressure gradients are achieved.

We now conduct an approximate analysis to the pumping mechanism depicted in figure 1. For an incompressible, laminar, and viscous liquid flow in a circular channel, the relationship between pressure drop and velocity can be obtained from the Hagen-Poiseuille equation, i.e.

$$
-\Delta P=\frac{32 \mu L u}{d^{2}}
$$

or

$$
u=\frac{d^{2}(-\Delta P)}{32 \mu L}
$$

where $L$ is the distance travelled by the fluid, and $\mu$ is the viscosity of the fluid. The fluid velocity at point $\mathrm{E}$ is due to both bulk motion of the liquid in section $\mathrm{OE}$ and the liquid evaporation at point $\mathrm{E}$, i.e.

$$
\frac{\mathrm{d} l}{\mathrm{~d} t}=u+u_{\mathrm{e}}
$$




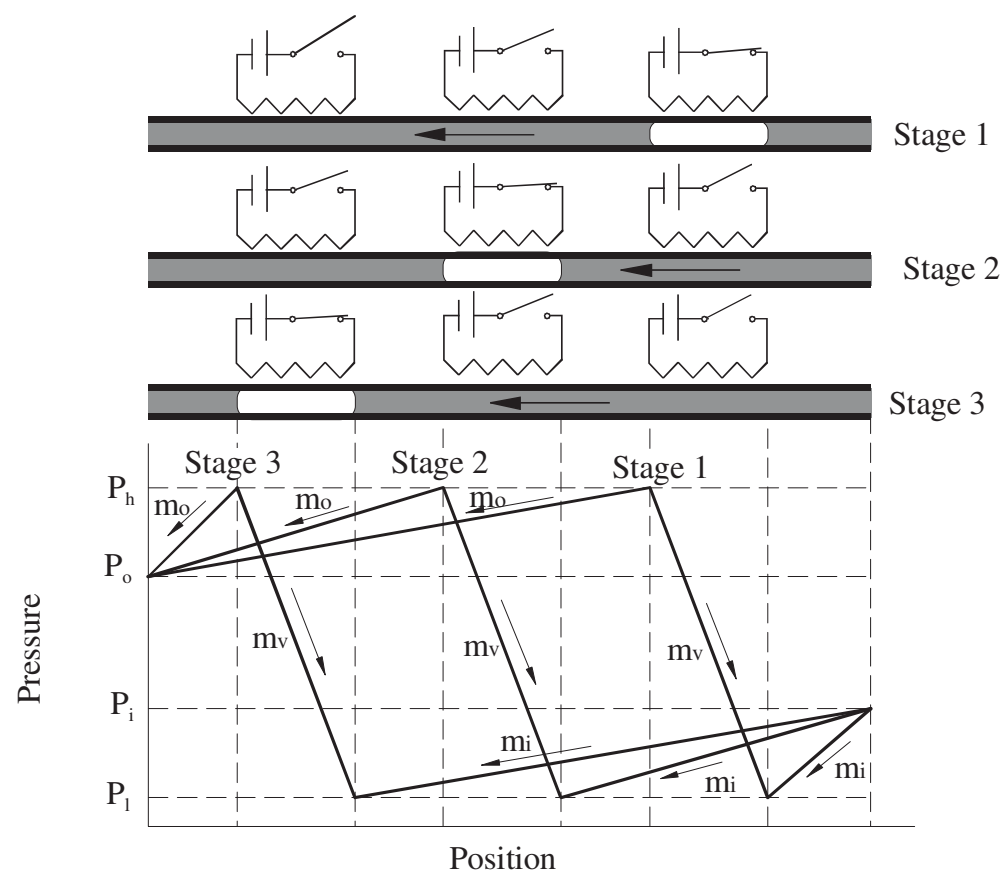

Figure 2. Illustration of the pumping mechanism.

where $l$ is the distance between points $\mathrm{E}$ and I. The moving velocity at point $\mathrm{E}$ caused by fluid evaporation $u_{\mathrm{e}}$ can be obtained by assuming that the applied heating power is completely used for evaporation such that

$$
u_{\mathrm{e}}=\frac{4}{\pi} \frac{q}{\gamma \rho d^{2}}
$$

where $q$ is the heating power, $\gamma$ is the evaporation latent heat, and $\rho$ is the density of the liquid.

Substituting equation (2) into (3) yields

$$
\frac{\mathrm{d} l}{\mathrm{~d} t}=\frac{d^{2}(-\Delta P)}{32 \mu l_{\mathrm{o}}}+u_{\mathrm{e}}
$$

where $-\Delta P=P_{\mathrm{h}}-P_{\mathrm{o}}, l_{\mathrm{o}}$ is the distance between points $\mathrm{O}$ and $\mathrm{E}$, and $l=L_{\mathrm{T}}-l_{\mathrm{o}}$. Letting $A=d^{2}(-\Delta P) /(32 \mu)$, equation (5) can be rearranged as

$$
\mathrm{d} t=\frac{L_{\mathrm{T}}-l}{\left(A+u_{\mathrm{e}} L_{\mathrm{T}}\right)-u_{\mathrm{e}} l} \mathrm{~d} l .
$$

Solving equation (6) subjected to

$$
\begin{cases}t=0 & l=0 \\ t=T_{\mathrm{o}} & l=L_{\mathrm{T}}\end{cases}
$$

we obtain

$$
T_{\mathrm{o}}=\frac{L_{\mathrm{T}}}{u_{\mathrm{e}}}+\frac{A}{u_{\mathrm{e}}^{2}} \ln \left(\frac{A}{A+u_{\mathrm{e}} L_{\mathrm{T}}}\right)
$$

where $T_{\mathrm{o}}$ is the time for the evaporation front $\mathrm{E}$ to travel from the inlet to the outlet. Based on equation (2), the mass flow rate of the fluid at the outlet, point $\mathrm{O}$, is

$$
m_{\mathrm{o}}=\frac{\mathrm{d} M_{\mathrm{o}}}{\mathrm{d} t}=\frac{\pi d^{4} \rho(-\Delta P)}{128 \mu l_{\mathrm{o}}} .
$$

Noting that $l_{\mathrm{o}}=L_{\mathrm{T}}-l$ and

$$
\mathrm{d} t=\frac{L_{\mathrm{T}}-l}{\left(A+u_{\mathrm{e}} L_{\mathrm{T}}\right)-u_{\mathrm{e}} l} \mathrm{~d} l
$$

equation (9) can be recast as

$$
\mathrm{d} M_{\mathrm{o}}=\frac{B}{\left(A+u_{\mathrm{e}} L_{\mathrm{T}}\right)-u_{\mathrm{e}} l} \mathrm{~d} l
$$

where $M_{\mathrm{o}}$ represents the total mass flow rate over the time period from zero to an instant $t$, and

$$
B=\frac{\pi d^{4} \rho(-\Delta P)}{128 \mu} .
$$

Integrating equation (10) subjected to the following boundary conditions

$$
\begin{cases}l=0 & M_{\mathrm{o}}=0 \\ l=L_{\mathrm{T}} & M_{\mathrm{o}}=M_{\mathrm{o}}\end{cases}
$$

we obtain

$$
M_{\mathrm{o}}=\frac{B}{u_{\mathrm{e}}} \ln \left(\frac{A+u_{\mathrm{e}} L_{\mathrm{T}}}{A}\right) .
$$

It follows from equation (13) that the average mass flow rate over the time taken for the evaporation front $\mathrm{E}$ to travel from the inlet to the outlet $T_{\mathrm{o}}$ is given by

$$
\bar{m}_{\mathrm{o}}=\frac{M_{\mathrm{o}}}{T_{\mathrm{o}}}=\frac{B \ln \left(\left(A+u_{\mathrm{e}} L_{\mathrm{T}}\right) / A\right)}{L_{\mathrm{T}}+\left(A / u_{\mathrm{e}}\right) \ln \left(A /\left(A+u_{\mathrm{e}} L_{\mathrm{T}}\right)\right)} .
$$

Similarly, the time taken for the condensation front $\mathrm{C}$ to travel from the inlet $T_{\mathrm{i}}$, the total amount of the liquid $M_{\mathrm{i}}$ entering into the channel over the time zero to time $t$, and the average mass flow rate $\bar{m}_{\mathrm{i}}$ during one cycle can be obtained as follows

$$
T_{\mathrm{i}}=\frac{L_{\mathrm{T}}}{u_{\mathrm{c}}}+\frac{C}{u_{\mathrm{c}}^{2}} \ln \left(\frac{C}{C+u_{\mathrm{c}} L_{\mathrm{T}}}\right)
$$




$$
\begin{gathered}
M_{\mathrm{i}}=\frac{D}{u_{\mathrm{c}}} \ln \left(\frac{C+u_{\mathrm{c}} L_{\mathrm{T}}}{C}\right) \\
\bar{m}_{\mathrm{i}}=\frac{D \ln \left(\left(C+u_{\mathrm{c}} L_{\mathrm{T}}\right) / C\right)}{L_{\mathrm{T}}+\left(C / u_{\mathrm{c}}\right) \ln \left(C /\left(C+u_{\mathrm{c}} L_{\mathrm{T}}\right)\right)}
\end{gathered}
$$

where $u_{\mathrm{c}}$ is the moving velocity of point $\mathrm{C}$ caused by vapour condensation

$$
C=\frac{d^{2}\left(P_{\mathrm{i}}-P_{1}\right)}{32 \mu}
$$

and

$$
D=\frac{\pi d^{4} \rho\left(P_{\mathrm{i}}-P_{1}\right)}{128 \mu} .
$$

When the micropump operates at a periodically steady state, we have

$$
T_{\mathrm{o}}=T_{\mathrm{i}}, \quad u_{\mathrm{e}}=u_{\mathrm{c}}, \quad M_{\mathrm{o}}=M_{\mathrm{i}} \quad \text { and } \quad \bar{m}_{\mathrm{o}}=\bar{m}_{\mathrm{i}}=m
$$

where $m$ represents the mass flow rate of the micropump. It follows from equations (8) and (15) that

$$
A \ln \left(\frac{A}{A+u_{\mathrm{e}} L_{\mathrm{T}}}\right)=C \ln \left(\frac{C}{C+u_{\mathrm{c}} L_{\mathrm{T}}}\right)
$$

and from equations (13) and (16) that

$$
B \ln \left(\frac{A}{A+u_{\mathrm{e}} L_{\mathrm{T}}}\right)=D \ln \left(\frac{C}{C+u_{\mathrm{c}} L_{\mathrm{T}}}\right) .
$$

From equations (14) and (17), we can obtain

$$
P_{\mathrm{h}}-P_{\mathrm{o}}=\frac{m\left[L_{\mathrm{T}}+\left(A / u_{\mathrm{e}}\right) \ln \left(A /\left(A+u_{\mathrm{e}} L_{\mathrm{T}}\right)\right)\right]}{\left(\pi d^{4} \rho / 128 \mu\right) \ln \left(\left(A+u_{\mathrm{e}} L_{\mathrm{T}}\right) / A\right)}
$$

and

$$
P_{\mathrm{i}}-P_{1}=\frac{m\left[L_{\mathrm{T}}+\left(C / u_{\mathrm{c}}\right) \ln \left(C /\left(C+u_{\mathrm{c}} L_{\mathrm{T}}\right)\right)\right]}{\left(\pi d^{4} \rho / 128 \mu\right) \ln \left(\left(C+u_{\mathrm{c}} L_{\mathrm{T}}\right) / C\right)} .
$$

For the section of the vapour slug, the mass flow rate is given by

$$
m_{\mathrm{ec}} \frac{\pi d^{4} \rho_{\mathrm{v}}\left(P_{\mathrm{h}}-P_{1}\right)}{128 \mu_{\mathrm{v}} L_{\mathrm{g}}}=\frac{q}{\gamma}
$$

where $\rho_{\mathrm{v}}$ and $\mu_{\mathrm{v}}$ represent the density and viscosity of the vapour, respectively. It follows from equation (25) that

$$
P_{\mathrm{h}}-P_{1}=\frac{q L_{\mathrm{g}} / \gamma}{\left(\pi d^{4} \rho_{\mathrm{v}} / 128 \mu_{\mathrm{v}}\right)} .
$$

Combining equations (23), (24) and (26) results in

$$
\begin{aligned}
P_{\mathrm{o}}- & P_{\mathrm{i}}=\frac{q L_{\mathrm{g}} / \gamma}{\left(\pi d^{4} \rho_{\mathrm{v}} / 128 \mu_{\mathrm{v}}\right)}-\frac{m}{\left(\pi d^{4} \rho / 128 \mu\right)} \\
& \times\left[\frac{L_{\mathrm{T}}+\left(A / u_{\mathrm{e}}\right) \ln \left(A /\left(A+u_{\mathrm{e}} L_{\mathrm{T}}\right)\right)}{\ln \left(\left(A+u_{\mathrm{e}} L_{\mathrm{T}}\right) / A\right)}\right. \\
& \left.+\frac{L_{\mathrm{T}}+\left(C / u_{\mathrm{c}}\right) \ln \left(C /\left(C+u_{\mathrm{c}} L_{\mathrm{T}}\right)\right)}{\ln \left(\left(C+u_{\mathrm{c}} L_{\mathrm{T}}\right) / C\right)}\right] .
\end{aligned}
$$

Note that

$$
A \ln \left(\frac{A}{A+u_{\mathrm{e}} L_{\mathrm{T}}}\right)=C \ln \left(\frac{C}{C+u_{\mathrm{c}} L_{\mathrm{T}}}\right)
$$

$$
\frac{A}{C}=\frac{P_{\mathrm{h}}-P_{\mathrm{o}}}{P_{\mathrm{i}}-P_{1}}
$$

and

$$
\frac{A}{C}+1=\frac{\left(P_{\mathrm{h}}-P_{1}\right)-\left(P_{\mathrm{o}}-P_{\mathrm{i}}\right)}{P_{\mathrm{i}}-P_{1}} .
$$

Therefore, equation (27) can be rewritten as

$$
\begin{aligned}
P_{\mathrm{o}} & -P_{\mathrm{i}}=\left(\frac{q L_{\mathrm{g}} \kappa_{\mathrm{v}}}{\gamma}-m \kappa\left(\frac{P_{\mathrm{h}}-P_{1}}{P_{\mathrm{i}}-P_{1}}\right)\right. \\
& \left.\times\left[L_{\mathrm{T}} / \ln \left(1+\frac{128 \kappa q L_{\mathrm{T}}}{\pi d^{4} \gamma\left(P_{\mathrm{i}}-P_{1}\right)}\right)-\frac{\pi d^{4} \gamma\left(P_{\mathrm{i}}-P_{1}\right)}{128 \kappa q}\right]\right) \\
& \times\left(\frac{\pi d^{4}}{128}+m \kappa \frac{1}{\left(P_{\mathrm{i}}-P_{1}\right)}\right. \\
& \left.\times\left[L_{\mathrm{T}} / \ln \left(1+\frac{128 \kappa q L_{\mathrm{T}}}{\pi d^{4} \gamma\left(P_{\mathrm{i}}-P_{1}\right)}\right)-\frac{\pi d^{4} \gamma\left(P_{\mathrm{i}}-P_{1}\right)}{128 \kappa q}\right]\right)^{-1}
\end{aligned}
$$

where $\kappa=\mu / \rho$ and $\kappa_{\mathrm{v}}=\mu_{\mathrm{v}} / \rho_{\mathrm{v}}$. Equation (28) gives the relationship between the pressure difference $\left(P_{\mathrm{o}}-P_{\mathrm{i}}\right)$ and the mass flow rate $(m)$ of the micropump under the design and operating conditions.

The head curve, the relationship between the volumetric flow rate $(Q=m / \rho)$ and the head $\left(H=\left(P_{\mathrm{o}}-P_{\mathrm{i}}\right) / \rho g\right)$, can be readily obtained from equation (28) as

$$
\begin{aligned}
H= & \left(\frac{q L_{\mathrm{g}} \kappa_{\mathrm{v}}}{\gamma \rho g}-\frac{Q \kappa}{g}\left(\frac{P_{\mathrm{h}}-P_{1}}{P_{\mathrm{i}}-P_{1}}\right)\right. \\
& \left.\times\left[L_{\mathrm{T}} / \ln \left(1+\frac{128 \kappa q L_{\mathrm{T}}}{\pi d^{4} \gamma\left(P_{\mathrm{i}}-P_{1}\right)}\right)-\frac{\pi d^{4} \gamma\left(P_{\mathrm{i}}-P_{1}\right)}{128 \kappa q}\right]\right) \\
& \times\left(\frac{\pi d^{4}}{128}+\rho Q \kappa \frac{1}{\left(P_{\mathrm{i}}-P_{1}\right)}\right. \\
& \left.\times\left[L_{\mathrm{T}} / \ln \left(1+\frac{128 \kappa q L_{\mathrm{T}}}{\pi d^{4} \gamma\left(P_{\mathrm{i}}-P_{1}\right)}\right)-\frac{\pi d^{4} \gamma\left(P_{\mathrm{i}}-P_{1}\right)}{128 \kappa q}\right]\right)^{-1} .
\end{aligned}
$$

Equation (29) predicts the head curve of the present phasechange micropump. Letting $Q=0$, equation (29) gives the maximum pressure head as

$$
H_{\max }=\frac{128 q L_{\mathrm{g}} \kappa_{\mathrm{v}}}{\pi d^{4} \gamma \rho g} .
$$

The maximum volume flow rate corresponding to zeropressure head is given by

$$
\begin{aligned}
Q_{\max } & =\left(\frac{q L_{\mathrm{g}} \kappa_{\mathrm{v}}}{\gamma \rho \kappa}\left(\frac{P_{\mathrm{i}}-P_{1}}{P_{\mathrm{h}}-P_{1}}\right)\right) \\
& \times\left(\left[L_{\mathrm{T}} / \ln \left(1+\frac{128 \kappa q L_{\mathrm{T}}}{\pi d^{4} \gamma\left(P_{\mathrm{i}}-P_{1}\right)}\right)-\frac{\pi d^{4} \gamma\left(P_{\mathrm{i}}-P_{1}\right)}{128 \kappa q}\right]\right)^{-1} .
\end{aligned}
$$

\section{Experimental investigations}

For the purpose of experimental investigations of the phasechange type micropump described in the previous section, an experimental set-up was built, as schematically shown in figure 3. The experimental apparatus consisted of a test section, a miniature liquid tank at the inlet of the tube, a liquid column (manometer) at the outlet of the tube, a dc power source, and a heater control system.

The test section consisted of twelve short Pyrex glass tubes having an inner diameter of $1.0 \mathrm{~mm}$ and a length of $31.0 \mathrm{~mm}$. All the tubes were connected in series and aligned in a groove 


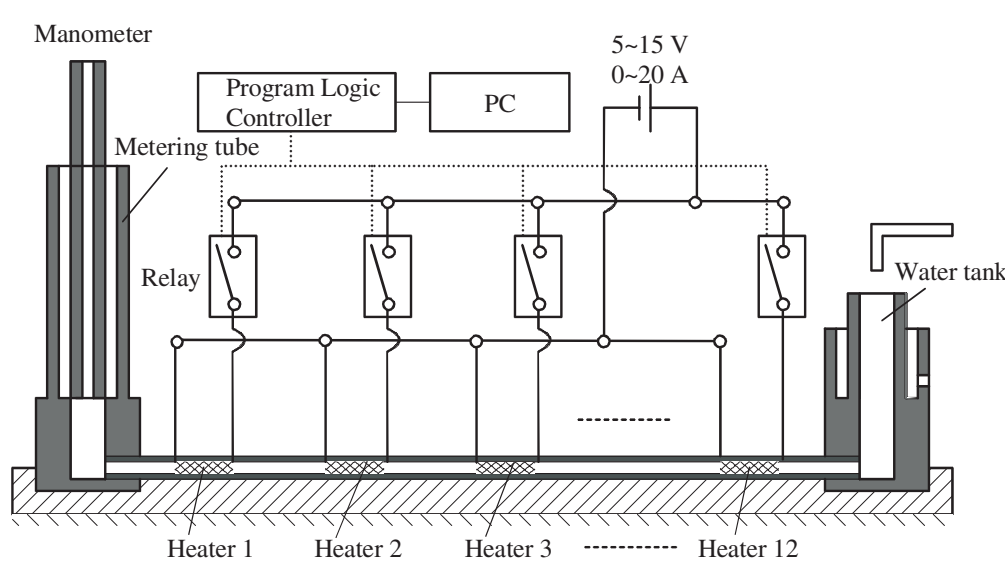

Figure 3. Experimental apparatus.

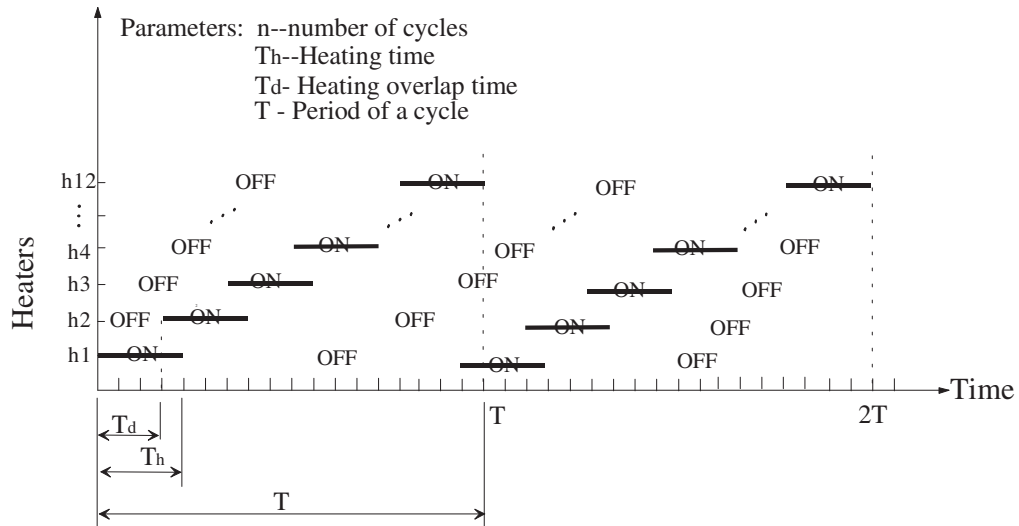

Figure 4. Chart of the heater operation scheme.

machined on a flat plate. A total of twelve identical miniature heaters were uniformly spaced along the test section. Each miniature heater was made of a Constantan wire $(0.2 \mathrm{~mm}$ in diameter, $100.0 \mathrm{~mm}$ in length and $1.15 \mathrm{Ohm}$ in electrical resistance), which was coiled to form a solenoid with an inside diameter of $0.6 \mathrm{~mm}$, an outside diameter of $1.0 \mathrm{~mm}$ and a length of $30.0 \mathrm{~mm}$. Each heating element was then inserted into each short tube such that the outer surface of the coiled wire was in intimate contact with the inner surface of the short tube.

As shown in figure 3 , all the heaters were connected to a dc power source through a control system consisting of twelve relays and a program logic controller (PLC) that was interfaced to a personal computer. The control system allowed us to vary some important parameters such as the heating power, the heating time of each heater, $T_{\mathrm{h}}$, the heating overlap time of the two consecutive heaters, $T_{\mathrm{d}}$, and the number of the operation cycles, $n$. The operation scheme of the twelve heaters is illustrated in figure 4.

As shown in figure 3, the working fluid, deionized water, was pumped from the miniature tank on the right to an eccentric annulus, formed by the manometer and a metering glass tube, on the left. The maximum head pressure of the pump was determined by the hydrostatic head difference between the meniscus height in the manometer at the outlet of the test section and the water level in the mini water tank at the inlet. The volumetric flow rate corresponding to a head pressure, which was adjusted by changing the liquid level in the manometer, was obtained by reading the liquid level rise in the annulus per unit time.

\section{Results and discussion}

Since the present test sections consisted of the Pyrex tubes with the Constantan solenoid insertions, an effective tube diameter is needed when equation (29) is used to predict the pumping performance. In view of the fact that the solenoids were tightly in contact with the inner surface of the Pyrex tubes and their pitches were rather small, the effective diameter, $d$, was obtained from

$$
d=d_{\mathrm{p}}-2 d_{\mathrm{o}}
$$

where $d_{\mathrm{p}}$ and $d_{\mathrm{o}}$ denote the diameters of the Pyrex tube and the Constantan wire, respectively. Based on equation (32), for the Pyrex tube with $d_{\mathrm{p}}=1.0 \mathrm{~mm}$ and the Constantan wire with $d_{\mathrm{o}}=0.2 \mathrm{~mm}$, the effective diameter for the test sections considered in this paper is $d=0.6 \mathrm{~mm}$.

The prediction by equation (29) also depends on the pressures at the both ends of the vapour slug, $P_{\mathrm{h}}$ and $P_{1}$. The pressure at the evaporation end of the vapour slug was estimated by measuring the temperature at the tube wall. It was found that the temperature at this end varied from 115 to $125{ }^{\circ} \mathrm{C}$. To simplify the analysis, we assumed that the temperature at this end was $120{ }^{\circ} \mathrm{C}$. The pressure at the condensation end of the vapour slug was determined by 


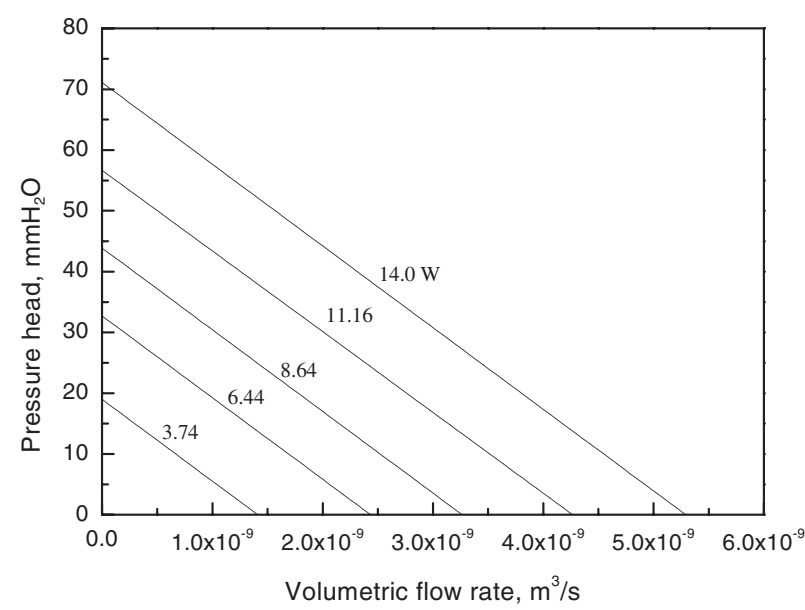

Figure 5. Predicted head curves.

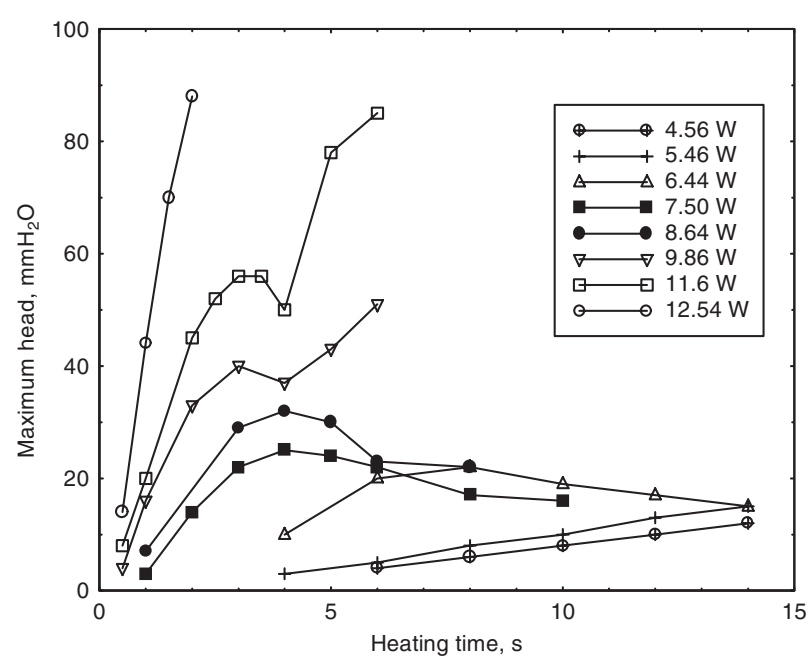

Figure 6. Measured maximum pressure heads versus heating time for various heating powers.

Table 1. Parameters used in the theoretical calculation. (Working fluid: degassed distill water.)

\begin{tabular}{ll}
\hline Parameter & Value \\
\hline$L_{\mathrm{g}}(\mathrm{m})$ & $30 \times 10^{-3}$ \\
$\mu_{\mathrm{v}}\left(\mathrm{Pa} \mathrm{s}^{-1}\right)$ & $1.32 \times 10^{-5}$ \\
$\rho_{\mathrm{v}}\left(\mathrm{kg} \mathrm{m}^{-3}\right)$ & 1.12 \\
$\kappa_{\mathrm{v}}=\mu_{\mathrm{v}} / \rho_{\mathrm{v}}\left(\mathrm{m}^{2} \mathrm{~s}^{-1}\right)$ & $1.179 \times 10^{-5}$ \\
$\gamma\left(\mathrm{J} \mathrm{kg}^{-1}\right)$ & $2.258 \times 10^{6}$ \\
$\mu\left(\mathrm{Pa} \mathrm{s}^{-1}\right)$ & $55.0 \times 10^{-5}$ \\
$\rho\left(\mathrm{kg} \mathrm{m}^{-3}\right)$ & 988.1 \\
$\kappa=\mu / \rho\left(\mathrm{m}^{2} \mathrm{~s}^{-1}\right)$ & $5.568 \times 10^{-7}$ \\
$P_{\mathrm{h}}(\mathrm{Pa})\left(\right.$ at $\left.120^{\circ} \mathrm{C}\right)$ & $1.986 \times 10^{5}$ \\
$P_{1}(\mathrm{~Pa})\left(\right.$ at $\left.20^{\circ} \mathrm{C}\right)$ & $2.338 \times 10^{3}$ \\
$P_{\mathrm{i}}(\mathrm{Pa})$ & $1.013 \times 10^{5}$ \\
$L_{\mathrm{T}}(\mathrm{m})$ & 0.38 \\
$d(\mathrm{~m})$ & $0.6 \times 10^{-3}$ \\
$\left.g(\mathrm{~m} \mathrm{~s})^{-2}\right)$ & 9.81 \\
\hline
\end{tabular}

assuming that the local temperature was the same as that of the working fluid at the inlet of the tube, i.e. $20{ }^{\circ} \mathrm{C}$.

The head curves of the phase-change type micropump, predicted by equation (29) and presented in figure 5, were obtained using the parameters listed in table 1 . The theoretical

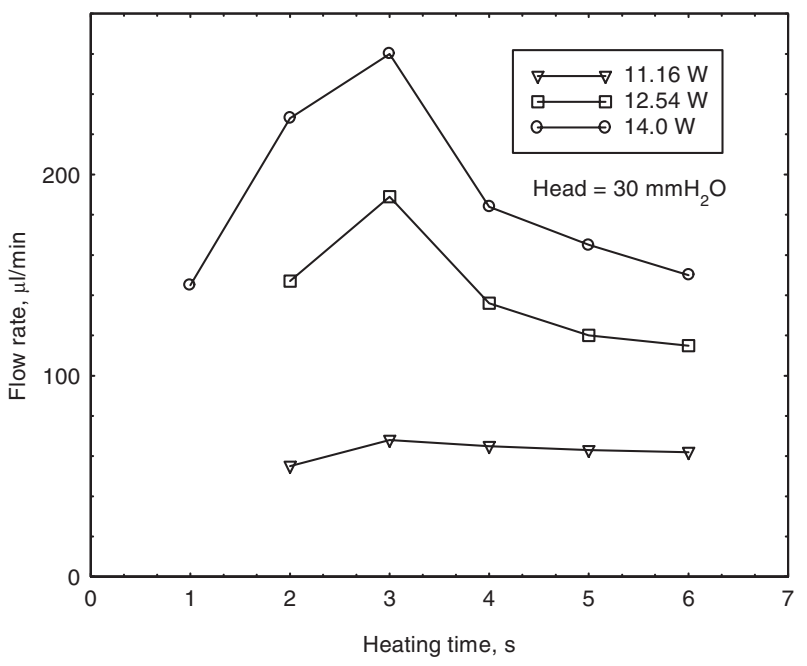

Figure 7. Measured volumetric flow rates for $30 \mathrm{~mm} \mathrm{H}_{2} \mathrm{O}$ pressure head.

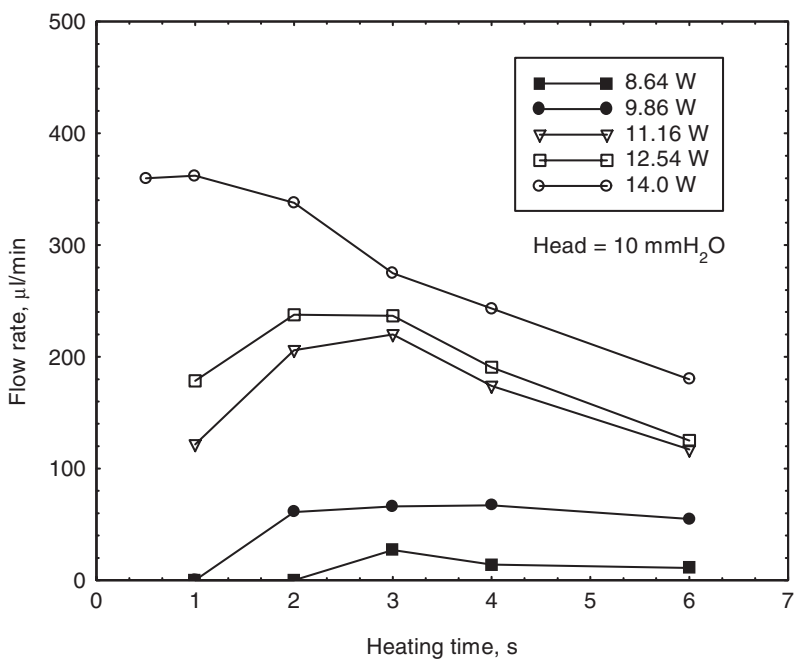

Figure 8. Measured volumetric flow rates for $10 \mathrm{~mm} \mathrm{H}_{2} \mathrm{O}$ pressure head.

prediction shows that when the heating power is varied from $3.74 \mathrm{~W}$ to $14.0 \mathrm{~W}$, the maximum pressure heads (corresponding to zero flow rate) are in the range of 19-71 $\mathrm{mm} \mathrm{H}_{2} \mathrm{O}$ (182.4-681.6 Pa) and the maximum volumetric flow rates (corresponding to zero pressure head) are in the range of 83.22$316.08 \mu 1 \mathrm{~min}^{-1}\left(1.387 \times 10^{-9}\right.$ to $\left.5.268 \times 10^{-9} \mathrm{~m}^{3} \mathrm{~s}^{-1}\right)$.

The measured maximum pressure heads versus the heating time for various heating powers are presented in figure 6 . The experimental results indicate that as the heating power for each heater was increased, the heating time for achieving the maximum pressure head became shorter. This is mainly attributed to the fact that a higher heating power leads to a fast bubble formation and growth. Figure 7 shows the variation of the volumetric flow rate with the heating time for different heating powers at a fixed pressure head of $30 \mathrm{~mm} \mathrm{H}_{2} \mathrm{O}$. It is interesting to note that for higher heating powers $(12.54 \mathrm{~W}$ and $14.0 \mathrm{~W}$ ), an optimum heating time existed at which the volumetric flow rate reached a peak value. As the heating power was reduced, the curve became flatter, implying that the pump performance is insensitive to the heating time for 


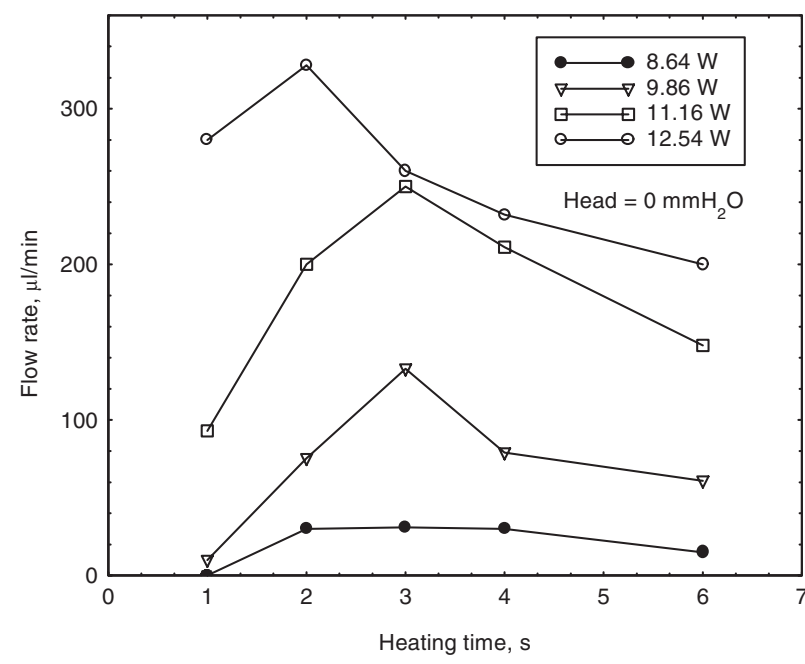

Figure 9. Measured maximum volumetric flow rates for zero pressure head.

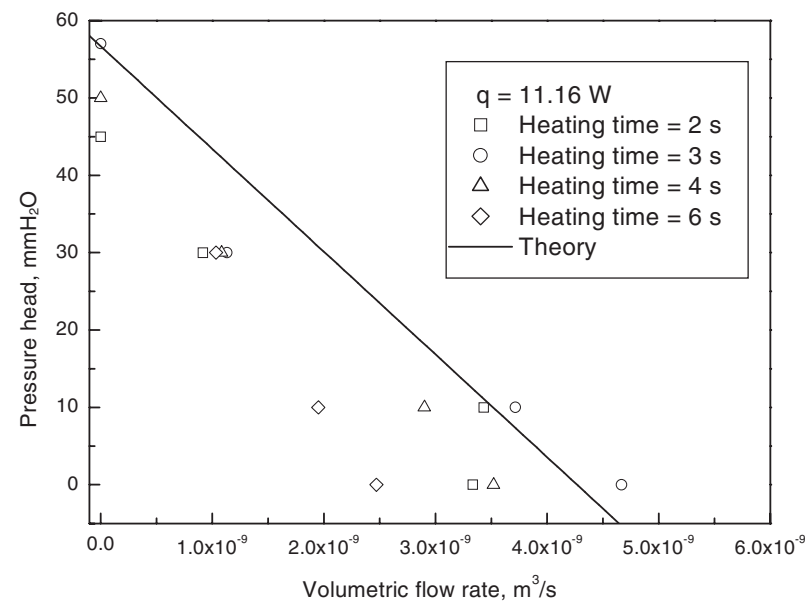

Figure 10. Comparison between experimental data and theoretical analyses.

low heating powers. Similar pumping behaviours can also be observed for small pressure heads of $10 \mathrm{~mm} \mathrm{H}_{2} \mathrm{O}$ and $0 \mathrm{~mm} \mathrm{H}_{2} \mathrm{O}$, as shown, respectively, in figures 8 and 9. Our experimental results suggest that for the present phase-change type micropump, the optimal heating power is in the range of 8.0-12.0 W while the optimal heating time is about $3 \mathrm{~s}$.

The experimental data for the case of the heating power of $11.16 \mathrm{~W}$ and the heating durations of 2.0, 3.0, 4.0 and $6.0 \mathrm{~s}$ are compared with the theoretical prediction in figure 10 . The comparison indicates that the theory can largely predict the trends of the heat curve although the present model is simple. It seems that more sophisticated models are needed to incorporate more parameters, such as the heating source moving speed and the delay time of the heaters, in order to make the theory more accurate.

\section{Concluding remarks}

A micropump actuated by suitably phased growth and collapse of vapour bubbles generated by microheaters in a liquid-filled microchannel has been fabricated and tested. In comparison with the traditional, moving-parts pumps, the striking features of this new micropump include its simplicity, no-moving-parts, ease of manufacture, and an ability to directly handle both pure fluids and also particulate-laden fluids. The experimental results indicate that this simple micropump can achieve a maximum pressure head of about $60 \mathrm{~mm} \mathrm{H}_{2} \mathrm{O}$ and a maximum volumetric flow rate of $300 \mu \mathrm{l} \mathrm{min}^{-1}$ when it is operated for a heating power ranging from $8.0-12.0 \mathrm{~W}$ and a heating time of about $3 \mathrm{~s}$. Better pumping performance of this type micropump is expected when the microchannels and the microheaters are fabricated in a single chip using MEMS techniques because the microfabricated system will provide a fast thermal response and facilitate a precise control of phased growth and collapse of vapour bubbles. The theoretical model is in reasonable agreement with the experimental data, predicting the trends of the head curve of the thermally driven phase-change nonmechanical micropump.

\section{Acknowledgments}

This work was supported by the Hong Kong RGC Earmarked Research Grant No. HKUST 6178/00E. The authors wish to express their gratitude to Professor ZY Guo for helpful discussions. The senior author (TSZ) gratefully acknowledges the Visiting Scholar Foundation of the State Key Laboratory of Multiphase Flow in Power Engineering at Xi'an Jiaotong University.

\section{References}

[1] Shoji S, Esashi M and Matsuo M 1988 Prototype miniature blood gas analyzer fabricated on a silicon wafer Sensors Actuators 14 101-7

[2] Gravesen P, Branebjerg J and Jensen O S 1993 Microfluidics-a review J. Micromech. Microeng. 3 168-82

[3] Verpoorte E M J, Schoot B H and Jeanneret S 1994 Three-dimensional micro flow manifolds for miniature chemical analysis systems J. Micromech. Microeng. 4 246-56

[4] Jun T K and Kim C J 1998 Valveless pumping using traversing vapor bubbles in microchannels J. Appl. Phys. 83 5658-64

[5] Morney R M, Whilt R M and Howe R T 1991 Ultrasonic induced microtransport Proc. IEEE MEMS Workshop'91 pp 277-82

[6] Harrison D J, Seiler K, Manz A and Fan Z 1992 Chemical analysis and electrophoresis systems integrated on glass and silicon chips Tech. Dig. IEEE Solid-State Sensors and Actuators Workshop pp 110-3

[7] Bart S F, Tavrow L S, Mehregany M and Larig J H 1990 Microfabricated electrohydrodynamic pumps Sensors Actuators A21-23 193-7

[8] Lin L, Pisano A P and Lee A P 1991 Microbubble powered actuator Transducers'91 pp 1041-4

[9] Bergstrom P L, Ji J, Liu Y N, Kaviany M and Wise K D 1995 Thermally driven phase-change microactuation J. Microelectromech. Syst. 4 10-17

[10] Takagi H, Meada R, Ozaki K, Parameswaran M and Mehta M 1994 Phase transformation type micro pump Proc. Int. Symp. on Micro Machine and Human Science (Piscataway, NJ: IEEE) 94TH0707-0 pp 199-202

[11] Ozaki K 1995 Pumping mechanism using periodic phase changes of a fluid Proc. IEEE Micro Electro Mechanical System (Piscataway, NJ: IEEE) 95CH35754 pp 31-6

[12] Jun T K and Kim C J 1996 Microscale pumping with traversing bubbles in microchannels Solid-state Sensor and Actuator Workshop (Hilton Head, SC, USA) pp 144-7 